\section{El impuesto ambiental de la reforma tributaria}

Evangelina Dardati* y Ramiro De Elejalde **

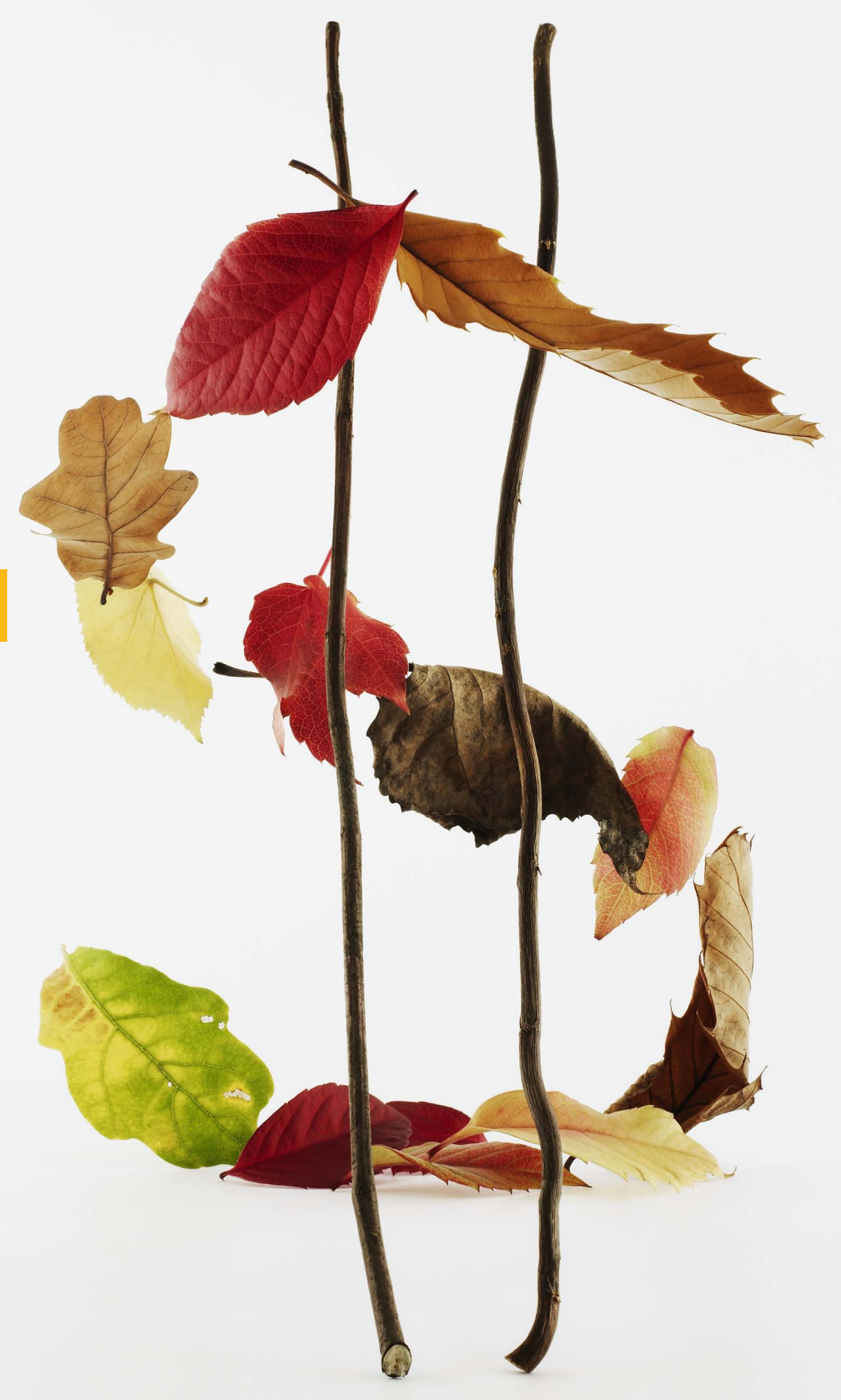

diseño de esta nueva política de impuestos. El impuesto a las emisiones al aire fuentes fijas grava las emisiones de Material Particulado (MP), Oxidos de Nitrógeno (NOx), Dióxido de Azufre (S02), y Dióxido de Carbono (CO2) por parte de calderas turbinas, con una potencia térmica mayor igual a 50 MWt (megavatios termicos). Una observacion inicial es el carácter discriminatorio de la ley. ¿Por que asignar nos $y$ fundiciones, por ejemplo? ¿Por que gravar solamente las fuentes fijes de mayor tamaño? ¿Y las fuentes móviles? Una explicación posible es la dificultad en fiscalizar ciertas actividades económicas de menor búsqueda de apoyo de ciertos sectores que se opondrian a este impuesto.

El pasado 1 de abril, la presidenta Bachelet presentó al pais el proyecto de ley de reforma tributaria. Una novedad importante es la incorporación de impuestos medioambientales, tambien llamados impuestos "verdes", que plantean un impuesto a las misiones de las fuentes fijas y otro a vehEl pincipa ojeas.

Es do un individuo o empresa efectúa un tividad que genera costos en terceros que no los tienen en cuenta. En este caso, la externalidad es la contaminación del aire y e objetivo del impuesto es que los individuos empresas que contaminan internalicen el daño que producen en el resto de la socie-

uestos, a diferencia de las politicas de comando y control, son una manera eficiente de controlar la contaminación géneas las politics de coras son heteroobligan a implementer ciertos estándar in discriminar las diferencias en el costo de disminuir las emisiones entre las diferentes fuentes. Un impuesto, en cambio, permite que algunas de ellas prefieran pagarlo antes de reducir las emisiones y otras, prefieran reducir las emisiones antes que pagar el impuesto. Dichos impuestos permiten entones, la misma disminución en las emisiones un costo menor. En este sentido, su implementación es una mejora de la política

taminación atmosférica de efecto globa

(CO2) como la contaminación atmosferica de efecto local (MP, NOx y S02). Sin embargo, la politica optima para Chile es muy En nu entra caso.

En nuestra opinión, un impuesto a la bal como el impuesto al CO2 no es unobuena politica pública para el pais Reconocemos que el calentamiento global es un problema de primer orden, pero la contribución de Chile a la emisión global de $\mathrm{CO} 2$ es infima. Por lo tanto, incurrir en un costo para no obtener ningún beneficio no parece una gran idea. Como argumentamos en el articulo "Protocolo de Kioto: ¿Vale pena reducir nuestras emisiones de $\mathrm{CO}_{2}$ ? (Observatorio Económico № 71), para logra controlar la emisión de $\mathrm{CO} 2$ es necesario que primero exista un acuerdo multilatera Rusia y Europa

Rusiay Europa. atmosférica de efecto lo lantaminación puesto a la emisión de Material Particulado (MP), Óxidos de Nitrógeno (NOx), y Dióxido de Azufre (S02). El MP son pequeñas partículas de polvo y los otros dos son gases que, junto con otros factores, llevan a formación de la denominada lluvia ácida Los tres contaminantes tienen efectos adversos en la salud de las personas. En este caso, el impuesto tiene una clara justificación económica. El siguiente grático muestamaño. Otra razón, tendría que ver con la

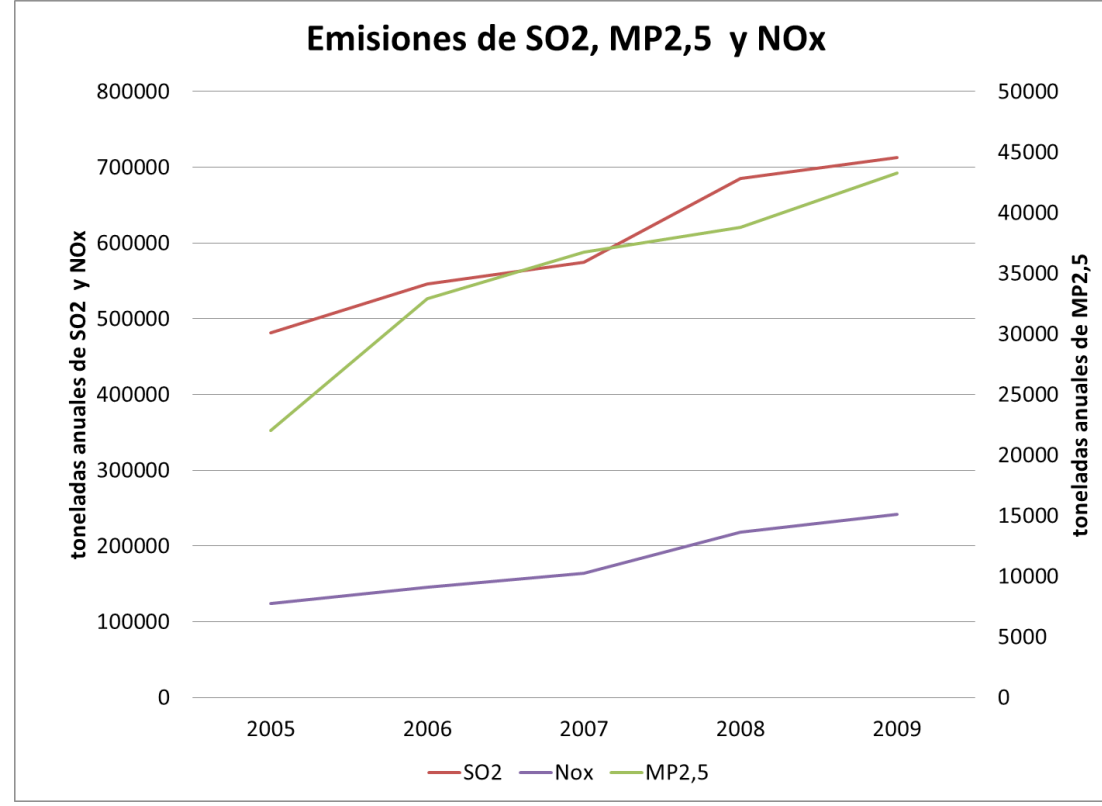
entre los grandes emisores de Dioxido de contaminantes).

tes entre 2005-2009.

A pesar que el impuesto serviría para dudas en cuanto a la implementación de dicho impuesto. Este tema es crucial, ya que una política mal implementada nos zar, se estipula un impuesto que depende de un factor de emisión específico (por do por el costo social por comuna y por contaminante. El costo social se refiere a Comion e factor ic emision pormar, entonces, Qué sucederá si una fuente conuna? Qn un lugar pero esa contaminación se aslada luego a otra zona? En ese caso, el factor de emisión de una comuna podría ser bajo, pero todas las fuentes ubicadas ahi podrian estar perjudicando otro sector y no se estaría internalizando el costo de sin analizar cuidadosamente sus consea efectos no deseados que después serán dificiles de reverti. Finalmente, la reforma establece un veriss falencios Primero, están exentos de mpuesto aquellos automóviles destinados transporte de pasajeros camiones cadionetas, furgones, tractores y otros similares. Segundo, en lugar de imponer el consumo de diésel se grava la importación de vehiculos con este combustible. Ninguna de estas aracteristicas tiene sentido desde un pun to de vista económico porque, si se quiee corregir la externalidad generada por el a consumo de diésel y el carácter discriminatorio del impuesto no se entiende por razotor de ínuesto ramente recaudatorio.

En sintesis, creemos que la regulación ambiental tiene algunos elementos positivos, como la utilización de una politica de incentivos para reducir los contaminantes ocales. Sin embargo, tenemos muchas dudas respecto a la correcta implementación de la misma. Un impuesto al CO2 lo consideramos innecesario y el impuesto a los
Fuente: Elaboración propia en base a datos del RETC (registro de emisiones y transferenci puede dejar peor que antes. Para empecomuna y por contaminante), multiplicalos gastos de salud. Esta formula implica la externalidad. Implementar una politica

vanos con un monto fijo que depende, fit de los mismos. Este impuesto

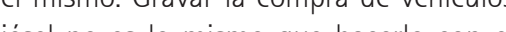

